\title{
Chapter 4 \\ Rezistans Klimatik: Building Climate Change Resilience in Haiti through Educational Radio Programming.
}

\author{
Ashley Bazin and Christelle Saintis
}

\subsection{Introduction}

It is almost 5 p.m., in a market in Port-au-Prince. A merchant, noting the time, flips open his phone and places it on top of his papitas (plantain chips) and candy basket, waiting for the familiar jingle that announces the beginning of a radio segment. If you observe the current activity in the market, merchants and customers alike are listening to the radio broadcast. At the same time, the chatter in the car of a family of 4 lulls into silence as a parent raises the volume of the radio. The other parent encourages the kids to pay attention, as it is educational, and the 10- and 14-yearold youths listen begrudgingly.

The Port-au-Prince population has been tuning in every day on their radios in order to learn how human behaviors are negatively affecting the environment in their country of Haiti. They are seeking to learn how they can decrease the impact of climate change, as well as how to respond to climate-related disasters. This learning opportunity is especially important for the merchant; since they did not attend school, it is the only way they can educate themselves. In the short time they have been tuning in, the fictional characters in the radio show have become as familiar to them as their own friends and the customers they serve each day. In the episodes, the main characters face critical issues concerning climate change that reflect the local context; the decisions that they make and discussions they have on the program are a reality for many of the people of Haiti. The street merchant and family can relate to the fictional characters and have begun adopting and incorporating some of the suggestions into their lives, as well as discussing the episodes with friends and family.

\author{
A. Bazin $(\bowtie) \cdot$ C. Saintis \\ Harvard Graduate School of Education, Cambridge, MA, USA \\ e-mail: abazin@gse.harvard.edu
}


Scenarios such as the two described are part of the daily routines of the Haitian population. While a variety of content is broadcasted via the radio, it is often informational by nature and educational for the listening population. This form of media is even more impactful amongst those who have little to no formal education. Radio programming substantially raises understanding of matters, such as climate change, educating both the formally educated and non-formally educated. The widespread use of radio in Haiti, due to its accessibility, is a factor that we considered when designing a program to help mitigate climate change and build resilience among the population of this island nation. It is undeniable that climate change is one of the most critical issues facing the planet at this moment. Addressing this issue has come to the forefront of international conversations as research and interactions with the environment have rendered the dialogue concerning climate change no longer a choice but a necessity. As it pertains to Haiti, the population experiences the increasing severities and fatalities of climate change every year. There is not a question of their awareness of climate change, however, the goal is to provide a solutions-oriented, comprehensive and science based information of these climatical occurences.

The report, Education \& Climate Change (Commonwealth Education Hub 2015), acknowledged that mitigating climate change requires collective action as a global community. There is a need for a shift in the global culture, improvement in human-decision making regarding their climatic behavior, as well as an increased awareness of the causal relationship between people and the health of the planet. This is especially important, as more countries become more industrialized, concluding in larger carbon footprints, thus exacerbating climate change and its' impacts - which disproportinately affects developing countries such as Haiti. One meaningful way to address this necessary shift is through education, which can provide agency, inform and motivate all inhabitants of this planet, including local community members and governments (Commonwealth Education Hub 2015).

The issue of climate change is most pressing to developing countries and islandstates that are very susceptible to the impact of changes in the environment (UNESCO 2012). One of the most vulnerable countries in the world to climate change is Haiti (Slagle and Rubenstein 2012). This chapter examines how education can help to mitigate climate change in Haiti by building the resilience of the citizens through educational radio programming. We consider climate change resilience in the context of Haiti to be the ability of the people to maintain a certain level of functioning while absorbing the effects imposed upon them by changes in the climate, as well as their capacity to adapt and evolve in ways that improve sustainability, leaving citizens better prepared for the future as impacts of climate change increase (Folke 2006; Nelson et al. 2007).

In this chapter, we explore the following: (a) a comprehensive assessment of current, retrospective and prospective impacts of climate change in Haiti; (b) an analysis of the two-way relationship between climate change and human behavior; (c) an analysis of the use of education to mitigate climate change in Haiti; (d) an examination of the current educational policies and programs currently being implemented globally to mitigate the impact of climate change, informal learning, and how media can develop sustainable practices; (e) the potential implications of climate change 
education in Haiti as assessed against given criteria; (f) an overview of the modes of media in Haiti; (g) a theory of change for the radio programming; (h) and finally, the implementation plan demonstrating the measures to be executed in order to have an effective program and fulfill the goals.

\subsection{Analysis of Current and Anticipated Impacts of Climate Change in Haiti}

\subsubsection{Geography}

Haiti is a tropical island-country located in the hurricane belt. According to the United Nations Development Program (UNDP) adaptation website (n.d.), Haiti has a total land area of $28,000 \mathrm{~km}^{2}$, and approximately $70 \%$ of the island is mountainous, thus the indigenous Taino moniker Ayiti, meaning "land of high mountains" (Ng Cheong-Lum 2005). The country has experienced both natural and man-caused hazards. The current environmental issues include active and extensive deforestation, soil erosion, and overpopulation, which impacts the distribution of potable water. The country is also subject to severe storms from June to October, droughts, flooding/threatening sea-levels, landslides, and earthquakes. Currently, only $3 \%$ of the country has forest cover, making way for agriculture and fuel production used for $71 \%$ of Haiti's energy requirements (CIA, 2018).

\subsubsection{Economy}

Though overpopulation is an issue, according to the World Population Review (2020), the country continues to grow at a rate of $1.24 \%$ a year, but it will hit its peak in 2070 and then decline. It is the poorest country in the Western Hemisphere, with $80 \%$ of the population living in poverty. The livelihood of $70 \%$ of Haitians is dependent on agriculture, provided through small-scale subsistence farming. Agriculture is also 32\% of the composition of the Gross Domestic Product (UNDP n.d.). Due to its economy and geographic stance, Haiti is very susceptible to the potential damages inflicted by climate change, even more post the disastrous 2010 earthquake.

\subsubsection{Other Socioeconomic Factors}

Other factors that contribute to the observed lack of resilience to the risks of climate change include government capacity, population growth and density, agricultural dependency, poverty, history of armed conflict, economic sector, public health systems, and weak infrastructure (Singh and Cohen 2014). 


\subsubsection{Climate Summary - Comparative Approach}

According to the report Climate Risk Profile: Haiti (USAID 2017), the climate trends in Haiti since 1960 include rising average annual temperatures of $0.45^{\circ} \mathrm{C}$, most of which occur during the warmer months of the year, from June until November. There was also a rise in the number of hot days per year by 63 days, between 1960 and 2003. The average rainfall has decreased each decade by $5 \mathrm{~mm}$. Natural hazards, such as hurricanes, have not only grown in numbers but also substantially increased in intensity. Many of the low plain areas and coastal zones have also experienced more flooding.

The USAID report also predicted some of the trends expected in Haiti in the future, including average annual temperatures rising between $0.78^{\circ}$ and $2.16^{\circ} \mathrm{C}$ by the year 2050. Annual precipitation will continue to decrease by up to $43 \mathrm{~mm}$, with droughts being a common re-occurrence, thereby causing problems for agriculture and farmers. Despite the predicted decrease of annual rainfall, there is also the possibility that the rainfall may become more extreme. Hurricanes, which have devastated the country, will grow more intense by between $5-10 \%$. The surrounding sea level is also expected to rise by up to $0.4 \mathrm{~m}$ by the year 2030 (Climatelinks 2017).

\subsubsection{Future Impacts}

Many different sectors and industries stand to be affected by changes in the climate. Indicated below are several anticipated impacts that will occur if Haiti does not address climate change.

\subsubsection{Agriculture}

In the future, climate change will most likely impact farming and agricultural export operations, which contribute significantly to Haiti's GDP. Furthermore, if rainfall declines and the temperature continues to rise, crop yields will be affected and negatively modify the country's nutrition, as well as families' ability to earn and children's ability to go to school. Also, the impact on the viability of agriculture will result in a decrease in Haiti's competitive edge on crops such as coffee, cacao, and mango in the international market (Smucker et al. 2007).

\subsubsection{Health}

Climate change will significantly worsen the already weak health system in Haiti. The stressors imposed by climate change will increase the disease burdens and exacerbate existing health issues, such as outbreaks of both vector and waterborne 
diseases. Natural hazards destroy road infrastructures decreasing accessibility to health services. The poor will suffer even more from an increase in malnutrition (Climatelinks 2017).

\subsubsection{Education}

Overall, damages to the road infrastructures will cripple the ability of students and teachers to travel to and from school. Also, school closings will be more common due to the instability of the buildings or their use as emergency shelters. Economic hardships, food security issues, and other factors impact school performance and attendance, leading to a regression in the quality of and access to the education system (Climatelinks 2017).

Beyond the external impacts on the educational experience, Haiti already has a feeble education system. A retroactive analysis of the education system that concluded in the adults of today is as follows. During the Duvalier era (1960-1980), one ran by a Father-Son dictatorial duo, there was a decline in the quality of education in Haiti because many qualified teachers fled the country due to political tension (Salmi 2000). According to Hadjadj (2000) - in the 1980s and 1990s, although there was a significant increase in the number of teachers, the quality of these teachers left much to be desired. Only $11.3 \%$ of primary school teachers held a professional degree (defined as teacher training school graduates and holders of teaching diplomas) in the $1980 \mathrm{~s}$, and $15 \%$ in the 1990s. Also, there was a significant number of "over-aged" students with, $53.2 \%$ of students being three or more years behind in relation to the legal age in 1980 and $48 \%$ in 1996.

\subsubsection{Economic Factors}

Climate change can result in the reduction of revenues, damages to a multitude of infrastructures (i.e., transportation and export), and a decrease in investor interest. Furthermore, it will involve the diversion of funds to cover the costs of damages caused by natural hazards. The exacerbation of the fragile economic sector will result in the entire country enduring the stressors imposed on them (Climatelinks 2017).

\subsubsection{Possible Domestic Solutions}

Given all these elements, in order to increase climate change resilience and decrease the negative outcomes of climate related disasters, Haitians need to adopt sustainable agricultural methods, engage in healthier volumes and types of consumption, and set forth policies that protect their part of Earth. 


\subsection{Connecting Climate Change to Human Behavior}

According to the scientists studying the causal relationship between humans and the environment, the current and problematic state of the climate is directly related to the choices and behavior of humans (Psychology and Global Climate Change 2009). Actions such as increasing population and consumption patterns have worked together to influence the changes in the environment. Individual predictors of consumption include income and skills, connection to nature, perceptions of needs versus luxuries, core psychological needs, etc. In turn, the implications of climate change for humans cannot be understated. Increasing levels of stress on the environment will inevitably lead to resources becoming scarce. At a psychosocial level, the scarcity in resources and preexisting inequalities will affect interpersonal and intergroup behaviors, possibly concluding in stress and anxiety. When considering this in the face of already existing competition and gaps in the wealth of countries and individuals, the effects will undoubtedly be profound. A potential positive consequence of climate change is international unity that can lead to us working collectively to mitigate the changes (American Psychological Association Task Force 2009) Indeed, acknowledging that the effects of climate change are not restricted to specific countries or regions but instead are felt worldwide, emphasizes this need for international collaboration.

Williamson, Satre-Meloy, Velasco, and Green (2018), made a case for a range of behavioral approaches to climate change, and acknowledge that individual behavioral changes, if on a large scale, can make a significant impact. They identified a total of 30 behavioral changes that can mitigate between $20-37 \%$ of global emissions for the next 30 years. Regarding human contributions to global warming, it has been occurring since the mid-twentieth century, via greenhouse gas emissions which are activated by decomposition, fossil fuel burning, and chemical fertilizers. Essentially, the cause of climate change is the imbalance between human-made deposits into the natural systems and the speed at which the natural system processes them. What is needed is an overall decrease in the consumption of raw natural resources by humans, specifically those of high-income countries. Additionally, they recommend: reduction in food waste, plant-rich diets, more efficient energy use, planting more trees, farmland restoration, conservative agriculture, reducing the use of fertilizer, installing irrigation systems, electric vehicles, mass transit, bicycles, solar rooftops, LED lighting, household water-saving and a slew of other behavioral solution to reduce our ecological carbon footprint.

Evans' (2019) research on Projected Behavioral Impacts of Global Climate Change is also relevant. He argues that global climate change can affect human behavior, including increased intergroup conflict (uptick in aggression and crimes), adverse mental health consequences (anxiety, suicide, etc.), deficits in cognitive developments, and Post-Traumatic Stress Disorder. Climate change alters the quality of life, which is foundational in mental health outcomes. The tipping point can be as simple as the restriction of outdoor recreational play resulting in psychological distress. 
Psychological approaches can also be deployed to modify human behaviors in ways that can reduce and potentially reverse the impact of climate change. Van Der Linden et al. (2015) described five best practices for improving public engagement with climate change. First, Social, Cognitive, and Clinical psychology have demonstrated that the human brain prioritizes direct personal experience over abstract occurrences. While data is necessary, in the effort of encouraging human behavior, it is ideal also to highlight climate change-related changes in the different ways a human experience it. Second, humans adhere to social and group norms. Humans, as a collective, influenced the climate changes we are currently witnessing; in order to change it for the better, it will require group effort. Therefore, concerning climate change, the sense of responsibility at the individual level is incredibly low. In the face of this issue, policymakers should try to stimulate positive behavior by reestablishing good prescriptive (how to behave) and descriptive (how others behave) norms. Third, there is a lack of urgency amongst humans; when making decisions, and evaluating costs and benefits, people discount uncertain future events. Due to the hazy knowledge of the future impacts of climate change, the consequences of climate change feel psychologically and physically far from the current moment for most people. One way to cultivate urgency is by bringing forth the current manifestations of climate change, explicitly recognizing regionally relevant impacts. Fourth, Van der Linden et al. argue that when it comes to climate change, people are prompted to take action when climate change losses are framed as a certainty that occurs in the present versus losses paired with uncertainty in the future. In response to that evidence, the conversation around climate change should be focused on the positive gains of immediate actions versus the potential losses of the future due to climate change. Lastly, to spur on a change in human behavior, human motivation should be used as a resource. Both intrinsic (caring for others) and extrinsic (money) motivations should be utilized. It is best to cater to both intrinsic and extrinsic motivations together because it is more sustainable, mainly due to climate change being a long-term environmental problem.

\subsection{Exploring Different Alternatives of Delivering Climate Change Education}

\subsubsection{The Use of Education in Addressing Climate Change}

It is essential in this analysis to understand what the existing literature states on education's role in combatting climate change. The 2015 United Nations' Sustainable Development Goals (SDGs) explicitly state the importance of education in helping to reach the goals by 2030 (UNESCO 2015). Many organizations have incorporated this urgency of education at the center of climate change action. The goals of these organizations are all related to the emphasis they place on the importance of climate action and the role education can play. 
The National Education Association (NEA), one of the two major national teacher unions in the United States, echoes the importance of educating society on the impact of climate change and global warming that are found in the SDGs (n.d.). They explain that teaching people the essential message that climate change not only exists but has implications and consequences for all humans and the Earth we share is paramount. The National Oceanic and Atmospheric Association (NOAA) has also laid out several key facts all students should know and understand, including that the effects of climate change can already be seen, that current infrastructures are in danger, and that climate change will likely threaten agriculture and thereby food security in the future (NOAA n.d.). All these factors are of great importance in the context of Haiti.

Curtailing the effects of this global crisis will involve all members of society not just politicians or those with access to information - and, therefore, will require a transfer of knowledge. In addition, learning from education is necessary because it is critical to address these issues immediately instead of only learning from experience (Ledley et al. 2017). Adequate and quality climate change education should emphasize the ability to achieve positive outcomes with activities framed around the gains that can be made by reducing individual footprints as well as the use of persuasive language to incite changes in behavior.

Addressing climate change through education is of global importance and is especially salient for the island nation of Haiti. If the country is to mitigate these effects, they must turn to education and recognize the crucial role it can play in helping to launch climate action in the country (Commonwealth Education Hub 2015). Indeed, education can support social change and significantly influence climate change mitigation, by increasing the number of citizens making informed decisions, regarding potentially destructive habits (Commonwealth Education Hub 2015). As stated by UNESCO, climate change education can help "people understand and address the impact of global warming, encourages changes in their attitudes and behavior and helps them adapt to climate change-related trends" (UNESCO n.d., para.1, 2010). Promoting a deeper understanding and awareness of the problems the planet and local communities are facing can help to shift public attitudes and ways of thinking on this topic. Education is also an essential part of helping individuals and communities learn to adapt to trends and empowers them to adopt lifestyles that are more sustainable (UNESCO 2010).

\subsubsection{Current Climate Change Curricula; Best Practices and Common Themes}

Most educational approaches to climate change involve work in formal education institutions. As important as working with children in school is, not all children attend school, and many adults have been in school for very few years. This reality 
calls for the development of non-formal and informal approaches to climate change education.

There are several institutions that have begun to create a climate change education curriculum, including The National Education Association (NEA), The National Oceanic and Atmospheric Association (NOAA), Stanford University, and UNESCO. In addition, several countries, such as China and Singapore, have begun to incorporate climate change curriculum into their education systems (Læssøe et al. 2009). In reading the literature, we were able to identify the successes and failures of different climate mitigation via education projects. Below is a list of the commonalities shared amongst the curriculum implemented around the world.

1. The integration of climate change into the school curriculum has been formulated to be a gradual and continuous mode of learning throughout the academic years. (Climate Curriculum n.d.)

2. In practice, many have integrated current data on climate systems into their STEM courses, including subjects such as Geography, Physics, Chemistry, etc. (Stanford Earth n.d.).

3. Others have opted for a more interdisciplinary approach, given the different ways in which climate change impacts people. For example, in S. Korea, the Education for Sustainable Development initiative included three perspectives: socio-cultural, environmental and economic based on the on-going realities of climate change in the country (Læssøe et al. 2009)

4. Another more pragmatic approach is Climate Change Education for Sustainable Development, which is an initiative promoted by UNESCO in developing countries such as the Dominican Republic. This type of education is focused on building local capacity through formal, non-formal, and informal projects. These projects in local communities are run by government agencies, civil society organizations, and empowered young leaders (UNESCO 2019).

\subsubsection{Government Action}

Despite the attempts to date, to combat the effects of climate change, Haiti's institutions still face numerous challenges at both the national and local levels. The scarcity in financial resources, the lack of technical capacity, the unreliable energy infrastructure, and the political instability prove to be obstacles in the process of allocating resources, and the implementation of different programs during times of disaster recovery. The attempts at achieving sustainable growth and development impacts the government's ability to provide essential services. These struggles exist during the regular occurrences of natural hazards and will continue to worsen with the incoming effects of climate change (Climatelinks 2017).

For example, the Dominican Republic piloted UNESCO's Climate Change Education for Sustainable Development (ESD) Program. This is especially pertinent given that the Dominican Republic and Haiti share the same island. In the 
Dominican Republic, climate change education has gained momentum since its inclusion in the Constitution of the country in 2010. In schools, ESD is taught in an interdisciplinary way using a variety of pedagogical practices in order to promote participatory learning. Training for teachers has been made available and includes support on building climate change into the curriculum as well as a research program that helps to promote sustainable development. Climate change education is focused on building local capacity through both formal, non-formal, and informal projects. These projects in local communities are run by government agencies, civil society organizations, and encourage the development of young leaders (UNESCO 2015). While these projects seem promising and could be applied in Haiti, financial constraints and corruption are some of the limitations of implementing these strategies (Gallagher et al. 2019). In addition, only 29\% of Haitians 25-and-older have attended secondary school, and approximately $50 \%$ of children do not attend school (Haiti Partners 2018). Due to these constraints and goals, the use of non-formal and informal means of delivering climate change information and education is more relevant in the context of Haiti.

\subsubsection{Informal Education}

Informal education encompasses any teachings outside the systematic organization of formal education. The typical characteristics of informal education include a decrease in contact between teacher and student, as well as learning taking place outside of an institution. Additionally, it is flexible, and the methodology varies in structure. This type of education does well in efficiently and effectively meeting the needs of a society because it is very functional and practical. Informal Education can be instrumental in developing countries due to its innate use of multidisciplinary strategies that are compatible with existing realities to mediate quandaries (Dib 1988).

In the context of Haiti, informal education is essential to reach the adult population. Working through the formal education system would prove ineffective for several reasons. It would further strain an already weak infrastructure, and with an existing scarcity of teachers and resources. Attempting to introduce climate change education formally may not reach as broad an audience and have as large an impact as informal education, especially when considering the high number of people out of school, or that have little-to-no formal education. Also, formal education as it pertains to climate change is essentially a long-term investment form of climate action. Due to the existing and dire circumstances of climate change, measures to be taken to mitigate the effects of it need to be quick and swift - therefore, using informal education can prove to be effective in rapidly accomplishing this. 


\subsubsection{The Use of Radio in Sustainable \& Community Development}

Authors, researchers, and activists have identified radio as a powerful and costeffective way of addressing issues of sustainability (Chapman et al. 2003; CIMA 2007; Jayaprakash and Shoesmith 2007; Khan et al. 2017; Sewlal 2014). There are several examples from different countries on the positive impact that radio has had on the communities and the spread of knowledge and information. Radio is more effective than other forms of media communication due in part to the low costs, access, reach, and portability (Jayaprakash and Shoesmith 2007).

In Ghana, for example, radio was used to improve the sharing of agricultural information in remote farming villages (Chapman et al. 2003). In Chapman et al.'s (2003) study, radio programs, which were broadcasted in the local languages, used drama performed by local actors along with discussions relating to the changes desired in the behaviors of the farmers, in order to determine if the radio show could influence positive behavioral change. The researchers chose the radio format to deliver the messages because of the strength of that media tool in reaching a broad audience, most of whom were illiterate, and provide them with the necessary information on agricultural production in a way that they understood. This meant using the local languages but also relaying the information in the local communities' agricultural vernacular, required understanding the farmers' knowledge of the subject before creating the program itself. The agricultural radio program in Ghana was successful in changing the behaviors of $94 \%$ of the farmers to behaviors that were more sustainable. Other direct results of the initiative were public debates on important matters, the introduction of new agricultural techniques, changes in public perceptions, as well as a balance between indigenous and scientific practices regarding agriculture. In this way, radio was able to address a more significant complex social problem, something that other countries have done as well.

In South Africa, the Soul City Project uses radio and other forms of media to address problems such as violence against women, HIV and AIDS, as well as other health issues (Chapmen et al. 2003). The educational messages delivered on the radio for the project are based around the process of 'edutainment,' which encourages debates and discussion on difficult and controversial topics, rather than simply dictating a message. The country uses the radio to give exposure to local issues, and broadcasting has helped with the development of small businesses, discussions on gender equity, consumerism, sports, music, and climate change (Sewlal 2014). By airing lessons and other forms of news and entertainment, these radio programs have been able to make tangible differences in the communities.

Some of the limitations of radio in sustainable and community development lie in a lack of funding, trained personnel, and poor leadership (Sewlal 2014). In many of the examples, the participatory nature of radio could be on the one hand empowering for localities while, on the other hand, challenging in terms of staffing capacity: since many stations rely on volunteers, problems can arise because of a lack of 
talent, time commitments, and high turnover rates (Sewlal 2014). Also, the operating and maintenance expenses can cut deeply into already thin funding.

Despite these limitations, radio remains the most accessible form of mass media and can capture broad audiences that are both literate as well as illiterate (Khan et al. 2017). It enlightens communities and can educate them on initiatives and strategies that will result in improvement in the lives of its listeners on issues surrounding agriculture, health, and environmental degradation, and more. It can also provide a lifeline to local communities in times of natural hazards (Sewlal 2014) and replace fear with hope through the sharing of information (CIMA 2007).

\subsection{Review of Current Education Policies and Programs to Address Climate Change in Haiti}

As previously explained, the importance of education in the fight against climate change cannot be understated. In response to global changes, Haiti must invest in developing and implementing comprehensive educational programs for society by addressing the concerns and solutions for climate change. There is existing research on the measures of resilience recommended for the government to consider when designing the efforts to rebuild after the earthquake (Singh and Cohen 2014). However, many of these efforts currently do not include a way to incorporate climate change in educational programs. Instead, many international organizations, such as USAID, have a focus on increasing government capacity and aiding the Ministry of the Environment. They also work to lead efforts in cutting back on behaviors that result in an increase in the effects of climate change (UNDP n.d.).

It is important to note that a necessity for the implementation of climate change programming in Haiti is funding. Financial constraints continue to be a substantial prohibitive factor in the country's efforts to combat climate change. Gallagher et al. (2019), analyzed the allocation of Haiti's financial assistance dedicated to Climate Change projects. They observed that this funding is dedicated to four of Haiti's 23 priorities for building resilience against climate change: food security, disaster risk reduction, renewable energy, and integrated water resource management. However, information and education are included in the list as a priority for the country, which highlights Haiti's recognition of education as a crucial part of its sustainable development and fights against climate change (Gallagher et al. 2019).

They also noted that some of the finances had been diverted to disaster recovery caused by regular environmental stressors, such as hurricanes. Otherwise, other matters such as agricultural adaptation, afforestation, coastal-zone management, capacity building, development of bioeconomy, etc. are relatively neglected. The analysis recorded a total of 76 climate change funded projects. Some date back to 6 years ago, but most were initiated after 2015 . Of these 76 projects, half were cat-

egorized as mitigation projects while the other half were considered adaptation projects. It is worth noting that, though active, there is no verification of the 
effectiveness of these programs. Gallagher et al. (2019) alluded to the lack of institutional regulations to combat climate change. They made recommendations regarding creating effective policies targeting different sectors, culminating in the creation of a comprehensive institutional environment that would be more mindful of the allocation of funding and reduce the need to manage all the climate change projects. However, a focus on education is not mentioned in their report (Gallagher et al. 2019).

Overall, Haiti is being reactive to climate change as opposed to proactive. As previously mentioned, most of the programming related to climate change in Haiti is either mitigating in nature or adaptive in approach. The lack of funding poses as a prominent obstacle in the goal of building resilience against climate change. In order to have a lasting effect, the country will have to adopt policies and programs that reach a broad audience, and this needs to have a two-tiered focus. Therefore, some policies and programming should focus on preventative measures of climate change, and others will have to target behaviors and choices at the community and individual level.

\subsection{Implications of Climate Change Education in Haiti}

Considering its vulnerability to climate change, the importance of educating the population in Haiti on how to mitigate these effects, as well as the impact on the local environment, cannot be understated. From the existing literature (Læssøe et al. 2009), there were several themes and best practices deemed most useful and relevant to the island nation's future climate action.

The first is the recurring theme of climate change education as a way to build skills. In Haiti, there is a critical need to develop the population's capacity to adapt to the changing environment. The population needs to learn how to make choices that are sustainable. For instance, what are the ways in which Haitians survive through. The ever-increasing number of severe natural hazards, such as hurricanes, to decrease the number of direct and related fatalities?

Second, learning that is related to the local environment and context is also essential. In some examples and cases found in the literature, the content of climate change initiatives is directly related to the context in which people live instead of including broad overarching knowledge about the phenomenon in general. This should work exceptionally well in Haiti; while Haitians are aware of climate change, given that they live through the increasing severities of natural hazards, being able to identify the intricate, comprehensive and scientific details of the effects that it has on their local environment would be very beneficial, in order to aid in the development of strategies to address and reduce the impact and limit the risk of future changes.

Third, in order to gain the skills necessary to survive, adapt, and minimize impact, an approach that reaches a relatively broad audience of people should also prove useful. In 2017, USAID reported that the majority of Haitians lack access to quality education. There are several challenges that Haiti faces concerning 
education. These include low school enrollments, poor literacy rates, lack of government oversight, and shortage of qualified instructors. Any program that wishes to make changes to the behavior of the general population should not focus on the school curriculum. Instead, a program that has widespread access to people who may not have the opportunity to benefit from a quality education makes the most sense.

In order to reach a broad audience, we must consider the media that is available. In the case of Haiti, the radio is the most popular form of media consumed in the country. Television (TV) is solely popular amongst folks who have access to electricity. Interestingly enough, radio stations have their corresponding TV Stations. Additionally, the average Haitian watches TV 4-6 h per week, and the peak time for watching is between $7 \mathrm{pm}$ and $10 \mathrm{pm}$ (Internews 2013).

Another form of media is newspapers, all of which are published in French in Haiti. In addition to the language it is written in and considering that newspapers do not rival radio in terms of popularity, the newspapers are a privilege of the elites; they are not accessible by at least half of the adult population due to lack of literacy in the French language. This relates to physical newspapers; though data concerning digital newspapers are not mentioned here, it is safe to infer that just as for TV, if there is no constant stream of electricity, then there is no Wi-Fi or computer, a reality for much of the country (Internews 2013).

Given these facts in the context of Haiti and the criteria of (1) wanting to reach a widespread audience, (2) half of the population not attending school, (3) many adults not being literate, and (4) a lack of televisions and a widespread use of radio, we identified educational radio programing as having the potential for the most impact in changing behaviors that lead to climate change resilience.

\subsection{Overview of Media in Haiti}

\subsubsection{Radio Use and Stats}

In Haiti, the radio is the most popular source of news and information (Internews 2013). This is due in part to few Haitians being able to afford to buy newspapers, and only half of the adult population being able to read and write. Many radio stations quote from the newspapers themselves, making the radio accessible and relevant to the broader community who cannot afford to buy newspapers or who cannot read.

According to the Media and Telecoms Landscape Guide (Internews 2013), almost every household in the country has a radio set, and, with the advent of the cell phone, many people now listen to the radio on their mobile devices as well. With more than 4.5 million people owning mobile handsets, the radio is very accessible to the broader population. In a media consumption survey on behalf of USAID, the local market research firm DAGMAR discovered that $96 \%$ of the people in the 
capital city of Port-au-Prince listen to the radio every day (Internews 2013). The survey also revealed high radio listening rates in nearby towns as well as in more distant villages.

Most of the people in Haiti listen to the radio for the news, with music, religious programs, and sports making up a smaller percentage of the reasons for listening. The survey showed that the preferred source of information was the radio, according to $83.7 \%$ of the respondents. Electricity is very unreliable in Haiti, making other media such as television more limited, with only $7 \%$ of people in the survey saying they preferred this source of media for the news and information; less than a third of Haitians have access to a TV at all.

\subsubsection{Radio and Learning in Haiti}

Since radio is the most accessible and most widely used media source in Haiti, much of the population who are not literate depend on it for their information. In the past, radio stations have informed listeners on educational topics, such as geography lessons and various catastrophes and consequences (Roca 2016). Locals have reported that the radio also serves to inform them on how to behave in society. For those who did not attend school and cannot read the newspapers, about half of the population, the radio can be one way that they learn. Many individuals tune in using their mobile phones, which allows them to access the radio from anywhere. This makes the radio a powerful tool in reaching the wider population and inciting change.

\subsection{Theory of Change}

The Theory of Change for adopting radio programing to educate for climate change is as follows: If the adult population in Port-au-Prince (1) listens to an educational radio program discussing specific behaviors, such as safety practices that should be taken during natural hazards and (2) changes their behaviors as a result of the radio program, then the resilience to climate change will increase among the population of adults in Port-au-Prince as people engage in behaviors that reduce the negative impact on their lives. We propose to implement this radio program in the capital as this is the area with the largest concentration of people as well as the most widespread use of radio. There are several different behaviors that the radio program could potentially focus on, such as responses to natural hazards, safety practices, and even sustainable agricultural practices. 


\subsubsection{Audience and Impacts of Project}

Many sustainable development educational programs target children. Though necessary, due to the dire circumstances in Haiti and the need to respond immediately to climate change-related disasters, we believe it would be best to target the adult population in order to spur on immediate changes in behaviors and build resilience. Furthermore, given that Port-au-Prince is the biggest city of the country, and houses 2.3 million of the 11 million citizens, we believe that this is the ideal location to target with the start of this project (World Population Review 2020).

Our goal is to address climate change by improving decision-making in order to increase resilience; therefore, we must consider the fact that those making most of the decisions in the adult population are not in school and have not been to school. As a result, reaching this population of adults will be the most effective using radio since only $7 \%$ of the population have televisions.

There are several domains that we see our project impacting. These domains are based on a framework for evaluating the impacts of informal science education projects (Friedman 2008). The domains this project will impact are (1) awareness, knowledge or understanding, (2) behavior, and (3) skills. Awareness, knowledge, or understanding refers to an impact that includes what the population in Haiti knows, in their own words, about the safety measures that should be taken during natural hazards. This knowledge should be determined before the start of the programming in order to ascertain any misconceptions that exist, and that can be addressed through the radio program. The knowledge impact category also refers to what people learn during, immediately after, or even long after the listening experience. Behavior refers to measurable changes in the exercise of behavior as related to the topic of safety measures and practices. Skills refer to any impact on the development or reinforcement of skills, in this case, new safety skills for responding to a natural hazard. Therefore, the definition of the best outcome for this project is defined as a shift in culture and behavior, prompting a productive response from the population to climate change issues (Radical Partners 2019).

Other concrete ways we plan on enabling the best outcomes include: designing a curriculum that is context-based and based on safety measures to be taken in response to climate change in Port-Au-Prince; producing a show based on the curriculum as mentioned earlier that is linguistically inclusive; pitch this initiative to the most-listened-to radio station which ensures widespread access; building on the sustainability of this project/show by maintaining good relationships with all stakeholders; and finally creating strict protocols on conduct, length, and material concerning the show. 


\subsubsection{Measuring Outcomes}

The intended goals and objectives of the radio program are improving knowledge surrounding safety practices, changing behavior, and developing the skills necessary to respond to natural hazards. In order to determine whether these goals were accomplished there is certain evidence we would have to collect to support our assertion that the program worked. Concerning the measurement of outcomes, the baseline would be the documentation of past climate change-induced disasters, specifically hurricanes. Every year between June and October, Port-Au-Prince experiences tropical storms/hurricanes. Due to climate change, these tropical storms have been increasingly more disastrous over the years. The outcome measurement would be a comparison of adaptive and recovery behaviors between post-earthquake storms and the storm that occurs after the broadcasting of this show. The analysis would question how people have tried to build resilience pre-storm and how they have tried to recover after the storm. It would also determine if there are differences between the magnitude of the aftermath pre-and-post the show. We would also incorporate a feedback system that would give us insight into how receptive the population is to our show and what their interests are.

Evidence for the impact on knowledge may come from changes in the listener's awareness and understanding of safety measures, which may be directly assessed through observations/surveys or self-reported. Evidence for changes in behavior might include speaking with residents in Port-au-Prince to determine any selfreported intentions to change their behavior, or even follow-ups longitudinally to see if changes in behavior have indeed occurred. Follow-ups might be particularly important to see actual behavioral changes. Finally, evidence for skills might include reflections from listeners or direct observations of the development or practice of new skills promoted in the radio program. Data can simply be gathered through Baseline surveys, which shall then be followed-up by either midterm or end-line surveys. We can try and gain insight into how useful they find the content to be, as well as what new practices they have engaged themselves in. Another form of data is utilizing third-party NGO research as insight into how the area has improved regarding climate change behavior.

\subsection{Implementation Plan/Curriculum}

\subsubsection{Stakeholders}

In assessing the implementation of this project, we worked on accounting for different stakeholders in order to identify how we may efficiently and effectively put this project into action. The first stakeholder is the audience, who are on the receiving end of this broadcast and whose behavior we hope to impact. We will try to broadcast our show on a popular radio station; therefore, the network who is willing to 
host our project is another stakeholder. Domestic climate change-related actions are typically launched by the government via different policies. There is a possibility of building a relationship with government personnel in order to tackle this problem together and devising how to change the culture. All other stakeholders represent the different moving pieces of this project, and this includes actors, writers, scientists, directors, producers, radio managers, financial managers, technical managers, programming manager, etc.

\subsubsection{Goal of Program}

The goal of the radio program is to bring awareness and influence the behavior of Haitians living in Port-au-Prince in order to increase their resiliency to the changes in the environment due to climate change. One huge impact of this is the growing number of hurricanes and natural hazards, which have plagued Haiti annually and have increasingly inflicted more damage to the people's quality of life. Ideally, we see this radio program as one part of a larger ongoing project that will eventually address a broad range of skills and behaviors that adults need to know in order to increase their resilience to climate change. Given the possible domestic solutions described previously, we envision these skills as blocks that would build on each other over time. While addressing safety practices during natural hazards is a priority and immediate concern, this is just a proposed starting point justified by the demographics of this specific context, as explained in the Audience and Impacts of Project section of this chapter.

\subsubsection{Topics Covered \& Objectives}

In our radio program, we will be addressing the concern of safety practices during natural hazards as the first in a series of topics. Being context-specific, the most recurring natural hazard is hurricane season; therefore, we will broach the topics of hurricane preparedness, measures to be taken during the hurricane, and how to recover post-hurricane all within the 'safety' frame. For example, one safety measure that the radio program will cover for pre-natural hazard is crafting an emergency plan that explains how to plan and protect yourself and family, shelter locations, and safety plans for those who live by the water. Post the natural hazard; listeners will learn what to avoid, such as power lines, damaged buildings, floodwaters, and wet electrical devices. A complete list of proposed topics to cover is in Appendix A.

Given that Port-Au-Prince is a metropolitan city, the most eminent impact of climate change has been Hurricane Season. However, a fundamental aspect of this project design is the accommodative and inclusive nature to all climate changerelated topics, as a significant piece is to be context-specific. There are broader 
skills and behaviors that Haitians need to learn in order to effectively build climate change resilience. For example, proper disposal of human waste and trash, how to preserve natural resources, as well as sustainable farming practices. A list of proposed topics that can be covered is in Appendix B.

\subsubsection{Strategy}

We propose a radio show that consists of ten 10-min short dramas. Table 4.1 shows the anticipated impact of radio shorts on behavior. The fictional series will broadcast several times a day on a commercial radio station that has a large following in Port-au-Prince. The 10-minute dramas will be integrated into the local news broadcast, preferably in the most popular radio station, which in the context of Haiti is Radio Caraibe.

The program will be broadcasted pre-, during, and post-hurricane season, which occurs every year between July and October. Out host radio station will play the educational drama series at different times during the day, modeling the frequency of commercials. We believe a repetitive cycle of broadcasting will have the highest impact, as displayed by previous efforts of radio programming (Chapman et al. 2003).

Table 4.1 Impact of radio shorts on behavior

\begin{tabular}{|c|c|c|c|}
\hline Impact & \begin{tabular}{|l} 
Impact \\
Category
\end{tabular} & Audience Objective & Evidence \\
\hline \multirow{3}{*}{$\begin{array}{l}\text { The listener will } \\
\text { change their } \\
\text { behavior or } \\
\text { acquire new } \\
\text { behaviors that } \\
\text { increase their } \\
\text { safety habits and } \\
\text { practices during } \\
\text { natural hazards }\end{array}$} & \multirow[t]{3}{*}{ Behavior } & $\begin{array}{l}\text { Listeners will have } \\
\text { an increase in } \\
\text { awareness of the } \\
\text { damages to be } \\
\text { anticipated and be } \\
\text { given tools to best } \\
\text { prepare for it. }\end{array}$ & \multirow{3}{*}{$\begin{array}{l}\text { Pre- \& Post-survey. This survey will act } \\
\text { both as evidence of behavioral changes, } \\
\text { as well as feedback from the audience. } \\
\text { We believe that a part of the sustainability } \\
\text { of the program lies in the consistent } \\
\text { evaluation of the effectiveness of this } \\
\text { program. Therefore, feedback is essential } \\
\text { for this process. This could be done } \\
\text { through baseline surveys followed up by } \\
\text { either a mid-term or end-line survey. }\end{array}$} \\
\hline & & $\begin{array}{l}\text { During the } \\
\text { occurrence of the } \\
\text { hurricane, listeners } \\
\text { will participate in } \\
\text { safety practices to } \\
\text { decrease the amount } \\
\text { of harm. }\end{array}$ & \\
\hline & & $\begin{array}{l}\text { Post-hurricane, } \\
\text { listeners will gain } \\
\text { the skills to easily } \\
\text { adapt and adjust to } \\
\text { the changes that } \\
\text { have occurred and } \\
\text { employ problem } \\
\text { resolution. }\end{array}$ & \\
\hline
\end{tabular}


Furthermore, referencing the reciprocal relationship between Climate Change and human behavior, in regard to content, we do intend to relay the information in a manner that prompts behavior by (1) framing climate change losses as a certainty that occurs in the present versus losses paired with uncertainty in the future, (2) activating human motivation by utilizing both intrinsic (caring for others) and extrinsic (money) motivation.

\subsubsection{Pathway for Delivery}

Ideally, we will propose this show to the top radio station, which is Radio Caraïbe, but others such as Radio Métropole, and Radio Lumière, are very popular.

\subsection{Discussion}

The implementation of this project requires effective leadership, and trained personnel in matters such as technical management, creative staff, programming, and financing. Haiti may be deficient in these resources, and we may have to take our involvement a step further and train individuals because a shortage in any of these areas is a threat to the sustainability of the radio show (Jayaprakash and Shoesmith 2007).

Although the international community has taken steps to address the issue of climate change, there is still a great deal of work to be done in the development and implementation of climate change education. As a nation at very high-risk for being affected by these changes, it is imperative that Haiti begins to address ways in which it can adapt to the already rapidly changing environment, as well as how it can strive towards mitigating the future impact of this global phenomenon. Based on the research evidence on the power of education in changing human behavior, which in turn minimizes environmental impact, education in sustainable development is recommended for the country.

Much of the information available on current climate change education shared overarching themes, without many examples of practical ways to best influence students and wider populations. Though we determined best practices in the available cases, the context of Haiti makes it difficult to adopt many of these. In order to prove successful and gain momentum, climate change education in Haiti must be approached in a systemic and multi-sectorial way that includes the common principle of participation and is focused on practical applications through a strengthening of resilience by building skills and capacities.

Our suggestion after reviewing the literature on informal education and the use of media in disseminating information, was for Haiti to approach mitigating climate change through an educational radio program. In this way, we believe we can reach a large audience and truly have an impact on changing behaviors towards those that 
are more sustainable. As the first step in a continuing series, we are looking at how people can better prepare for naturally occurring events, such as hurricanes, which can be devastating. Through educational radio programming, already the most popular way for people to get information, we believe that climate change resilience among the Haitian people can be increased for the better.

\section{Appendixes}

\section{Appendix A}

\section{Pre-Natural Hazards - Safety Measures}

1. The Difference between Hurricane Watch vs. Hurricane Warning

2. Putting together a basic disaster supplies kit: Basics, Additional, Maintenance and Storage Locations

3. Crafting an Emergency Plan: How to plan and Protect yourself and Family, Shelter locations, how to care for your pets, and safety plans when you live by the water.

4. Clean Up

\section{During Natural Hazards - Safety Measures}

5. Power Outage

6. Q\&A Session

\section{Post-Natural Hazards - Safety Measures}

7. What to Avoid: Power Lines, Damaged Buildings, Floodwaters, Wet electrical devices

8. What to do if you have been in floodwaters.

9. How to Prevent Carbon Monoxide Poisoning

10. Food and Water

11. Taking care of Emotional Health

\section{Appendix B}

\section{Other - Topics}

- How to preserve your natural resources: A focus on the decrease in the erosion of the land by humans and natural hazards.

- How to engage in industrial behaviors without generating extreme pollution and chemical exposure.

- How to properly dispose of human waste 
- How to properly dispose of trash

- For the farmer - how to maximize reaping what you sow, all while practicing preservative methods of farming the land

- Better Eating Habits: Plant-Based Lifestyle

- How can your family engage in Climate-Change Behavior?

- A discussion: What policies should as a collective implement for best practices.

- Dealing with anxiety as it pertains to Climate Change

- How to Prevent, Deal and Recuperate ... a PSA:

- Floods

- Droughts

- Tsunami

- Volcano

- Storms (Blizzard, Ice, Hail) Tornado

- Earthquake

- Wildfires

- Landslides

\section{References}

American Psychological Associations Task Force on the Interface Between Psychology and Global Climate Change. (2009). Psychology and global climate change: Addressing a multi-faceted phenomenon and set of challenges. Retrieved from https://www.apa.org/science/about/publications/climate-change-booklet.pdf

Center for International Media Assistance (CIMA). (2007). Community radio: Its impact and challenges to its development (Working group report). Washington, DC: CIMA. Retrieved from https://www.cima.ned.org/wp-content/uploads/2015/02/CIMA-Community_Radio-Working_ Group_Report_0.pdf.

Chapman, R., Blench, R., Kranjac-Berisavljevic, G., \& Zakariah, A. (2003). Rural radio in agricultural extension: The example of vernacular radio programmes on soil and water conservation in N. Ghana (Network paper no.127). London: Agricultural Research and Extension Network. Retrieved from https://www.odi.org/publications/4270-rural-radio-agricultural-extensiontheexample-vernacular-radio-programmes-soil-and-water.

Climate Curriculum. (n.d.). Climate lessons. Retrieved from https://www.climatecurriculum.com/ climate-lessons-1

Climatelinks. (2017). Climate risk profile. Haiti. Retrieved from https://www.climatelinks.org/ resources/climate-risk-profile-haiti

Commonwealth Education Hub. (2015). Education \& Climate Change. 29. Retrieved from https:// www.thecommonwealth-educationhub.net/wp-content/uploads/2015/12/Climate-ChangeDiscussion-Summary.pdf

van der Linden, S., Maibach, E., \& Leiserowitz, A. (2015). Improving public engagement with climate change: Five 'best practice' insights from psychological science. Perspectives on Psychological Science, 10(6), 758-763. https://doi.org/10.1177/1745691615598516.

Dib, C. Z. (1988). Formal, non-formal, and informal education: Concepts/applicability. AIP Conference Proceedings, 173, 300-315.

Evans, G. W. (2019). Projected Behavioral impacts of global climate change. Annual Review of Psychology, 70(1), 449-474.

Folke, C. (2006). Resilience: The emergence of a perspective for social-ecological systems analyses. Global Environmental Change, 16(3), 253-267. 
Friedman, A. (Ed.). (March 12, 2008). Framework for evaluating impacts of informal science education projects [On-line]. Available at http://insci.org/resources/Eval_Framework.pdf

Gallagher, K. S., Perry, K., Wansem, M., Kuhl, L., \& Frapaise, L. (2019). Analysis of international funding for Haiti's climate change priorities. SSRN Electronic Journal. https://doi. org/10.2139/ssrn.3333173.

Hadjadj, B. (2000). Education for all in Haiti over the last 20 years: Assessment and perspectives. Kingston: Office of the UNESCO Representative in the Caribbean.

Haiti Partners. (2018, January 18). Haiti statistics. Retrieved from https://haitipartners.org/ haiti-statistics/

Internews. (2013). Haiti media and telecoms landscape guide. Retrieved from https://internews. org/resource/haiti-media-and-telecoms-landscape-guide

Jayaprakash, Y. T., \& Shoesmith, B. (2007). Community radio and development: Tribal audiences in South India. In L. K. Fuller (Ed.), Community media (pp. 43-53). New York: Palgrave Macmillan.

Khan, M. A. A., Khan, M. M. R., Hassan, M., Ahmed, F., \& Haque, S. M. R. (2017). Role of community radio for community development in Bangladesh. The International Technology Management Review, 6(3), 94-102.

Læssøe, J., Schnack, K., Breiting, S., \& Rolls, S. (Eds.) (2009). Climate change and sustainable development: the response from education. A cross-national report from international Alliance of leading education institutes. Retrieved from https://www.dpu.dk/fileadmin/www.dpu.dk/ edusudclimatechangeandsustainabledevelopment/documents/om-dpu_institutter_institut-fordidaktik_20091208102732_cross_national-report_dec09.pdf

Ledley, T. S., Rooney-Varga, J., \& Niepold, F. (2017). Addressing climate change through education. Oxford Research Encyclopedia: Environmental Science. https://doi.org/10.1093/ acrefore/9780199389414.013.56

National Education Association (NEA). (n.d.). Climate change education: Essential information for educators. Retrieved from: http://www.nea.org//home/65564.htm

Nelson, D., Adger, W., \& Brown, K. (2007). Adaptation to environmental change: Contributions of a resilience framework. Annual Review of Environment and Resources, 32, 395-419.

$\mathrm{Ng}$ Cheong-Lum, R. (2005). Haiti (Cultures of the World) (2nd ed.). Tarrytown, NY: Marshall Cavendisk Benchmark.

NOAA. (n.d.) The essential principles of climate literacy. Retrieved from https://www.climate. gov/teaching/essential-principles-climate-literacy/essential-principles-climate-literacy

Radical Partners. (2019). 100 great ideas: Climate resilience \& sustainability. Retrieved from https://issuu.com/radical.partners/docs/climate_resilience__sustainability

Roca, C.C. (2016, April 14). Radio in Haiti is the heartbeat of the community. Miami Herald. Retrieved from https://www.miamiherald.com/news/nation-world/world/americas/haiti/article71931957.html

Salmi, J. (2000). Equity and quality in private education: The Haitian paradox. Compare: A Journal of Comparative and International Education, 30(2), 163-178.

Sewlal, R. (2014). The role and rise of community radio in the development of democracy in South Africa: 20 years of democracy. Rhodes Journalism Review, 2014(34), 24-26.

Singh, B., \& Cohen, M. (2014). Climate change resilience: The case of Haiti. Retrieved from www. oxfamamerica.org/explore/researchpublications/climate-change-resilience-thecase-of-haiti

Slagle T. \& Rubenstein, M. (2012, February 1). Climate change in Haiti. Retrieved from https:// blogs.ei.columbia.edu/2012/02/01/climate-change-in-haiti/

Smucker, G. R., Bannister, M., D’Agnes, H., Gossin, Y., Portnoff, M., Timyan, J., \& Toussaint, R. (2007). Environmental vulnerability in Haiti: Findings and recommendations. USAID/Haiti.

Stanford Earth. (n.d.). Climate change education: Curriculum. Retrieved from https://earth.stanford.edu/climate-change-ed/curriculum

The World Factbook: Haiti. (2018, February 01). Retrieved from https://www.cia.gov/library/ publications/the-world-factbook/geos/ha.html

UNESCO. (2010). The UNESCO climate change initiative: Climate change education for sustainable development. Retrieved from https://unesdoc.unesco.org/ark:/48223/pf0000190101 
UNESCO. (2012). Climate change education for sustainable development in small island developing states: Report and recommendations. UNESCO experts meeting 21-23 September 2011, Nassau, Commonwealth of the Bahamas. Retrieved from https://unesdoc.unesco.org/ ark:/48223/pf0000216473

UNESCO. (2015). Not just hot air: Putting climate change education into practice. Retrieved from https://unesdoc.unesco.org/ark:/48223/pf0000233083

UNESCO. (2019). UNESCO and sustainable development goals.. Retrieved from https:// en.unesco.org/sustainabledevelopmentgoals

UNESCO. (n.d.) 'Climate Change Education'. Retrieved from https://en.unesco.org/themes/ education-sustainable-development/cce

United Nations Development Program (UNDP). (n.d.). National adaptation plans in focus: Lessons from Haiti. Retrieved from https://www.adaptation-undp.org/resources/project-brief-fact-sheet/ national-adaptation-plans-focus-lessons-haiti

USAID. (2017). Climate risk profile. Haiti. Retrieved from https://www.climatelinks.org/sites/ default/files/asset/document/2017_Cadmus_Climate-Risk-Profile_Haiti.pdf

Williamson, K., Satre-Meloy, A., Velasco, K., \& Green, K. (2018). Climate change needs behavior change: Making the case for behavioral solutions to reduce global warming. Arlington, VA: Rare.

World Population Review. (2020). Haiti population 2020. Retrieved from http://worldpopulationreview.com/countries/haiti-population/

Ashley Bazin is a graduate of the Education Policy and Management Masters Program at the Harvard Graduate School of Education. She received her B.A. in Psychology from Rhode Island College and has done research in both developmental and cognitive psychology. Prior to attending HGSE, she worked at a state-wide, youth advocacy organization, for low-income High School students, assisting in their leadership development. Ashley has a vested interest in increasing the access to quality education for both youth and adults.

Christelle Saintis is a graduate of the International Education Policy Masters program at the Harvard Graduate School of Education. She received her B.A. in History from The George Washington University. Prior to her studies at Harvard, she taught Special Education in the Chicago Public Schools before moving abroad and teaching English in Thailand. Most recently, she taught at a bilingual school in Honduras. Christelle is passionate about language education in developing countries and promoting language policies that support bilingual education.

Open Access This chapter is licensed under the terms of the Creative Commons Attribution 4.0 International License (http://creativecommons.org/licenses/by/4.0/), which permits use, sharing, adaptation, distribution and reproduction in any medium or format, as long as you give appropriate credit to the original author(s) and the source, provide a link to the Creative Commons license and indicate if changes were made.

The images or other third party material in this chapter are included in the chapter's Creative Commons license, unless indicated otherwise in a credit line to the material. If material is not included in the chapter's Creative Commons license and your intended use is not permitted by statutory regulation or exceeds the permitted use, you will need to obtain permission directly from the copyright holder.

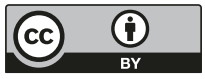

